\title{
Effect of n-3 polyunsaturated fatty acid on gene expression of the critical enzymes involved in homocysteine metabolism
}

\author{
Tao Huang ${ }^{1,2}$, Mark L Wahlqvist ${ }^{1,2,3}$ and Duo Li ${ }^{1,2^{*}}$
}

\begin{abstract}
Background: Previous studies showed that plasma n-3 polyunsaturated fatty acid (PUFA) was negatively associated with plasma homocysteine (Hcy).

Objective: We investigated the regulatory effect of n-3 PUFA on mRNA expression of the critical genes encoding the enzymes involved in Hcy metabolism.

Methods: HepG2 cells were treated with docosahexaenoic acid (DHA), eicosapentaenoic acid (EPA), alpha-linolenic acid (ALA) respectively for $48 \mathrm{~h}$. The cells were collected and total RNA was isolated. The mRNA expression levels of the genes were determined by using Real Time-PCR.

Results: Compared with controls, the mRNA expression levels of 5-methyltetrahydrofolate reductase (MTHFR) were significantly increased in the DHA group $(p<0.05)$ and ALA group $(p<0.05)$; Significantly down-regulated mRNA expression of methionine adenosyltransferase (MAT) was observed with the treatments compared with the controls; the level of MAT expression was significant lower in the DHA group than the ALA group $(p<0.05)$; Cystathionine- $\gamma$-lyase (CSE) expression was significantly increased in the DHA $(p<0.05)$ and EPA groups $(p<0.05)$ compared with control. No significant changes were shown in mRNA expression levels of S-adenosylhomocysteine hydrolases (SAHH), cystathionine $\beta$-synthase (CBS), and 5-methyltetrahydrofolate-homocysteine methyltransferase (MTR).
\end{abstract}

Conclusions: Our results suggest that DHA up-regulates CSE and MTHFR mRNA expression and down-regulates MAT mRNA expression involved in Hcy metabolism.

\section{Background}

Hyperhomocysteinaemia (HHcy) has been reported to be an independent risk factor for cardiovascular disease (CVD) [1]. Homocysteine (Hcy) is a thiol-containing amino acid derived from methionine metabolism [2]. In methionine metabolism, methionine is converted to Sadenosylmethionine (SAM) via methionine adenosyltransferase (MAT), which is the only methyl-donating pathway in humans [3]. S-adenosylhomocysteine (SAH), a product of this methyl-transferase reaction, is hydrolyzed to Hcy in a reversible reaction via the S-adenosylhomocysteine hydrolases (SAHH). Once synthesized,

\footnotetext{
* Correspondence: duoli@zju.edu.cn

'Department of Food Science and Nutrition, Zhejiang University, Hangzhou, 310029 China

Full list of author information is available at the end of the article
}

Hcy can be degraded through two enzymatic pathways: transsulfuration and remethylation (Figure 1) [1]. In remethylation, Hcy can be converted back to methionine in the remethylation pathway via 5-methyltetrahydrofolate reductase (MTHFR) and methionine synthase (MS) using cofactors such as vitamin $\mathrm{B}_{12}$ and folic acid [4]. In the transsulfuration pathway, Hcy is condensed with serine to form cystathionine via vitamin $B_{6}$ dependent cystathionine $\beta$-synthase (CBS), subsequently, cystathionine is converted to cysteine, $\alpha$-ketosuccinic acid, taurine, and hydrogen sulfide $\left(\mathrm{H}_{2} \mathrm{~S}\right)$ via vitamin $\mathrm{B}_{6}$ dependent cystathionine- $\gamma$-lyase (CSE) [5].

Variations in the levels of Hcy can be due to defects of the genes encoding the critical enzymes involved in methionine metabolism [6], nutritional status for folic acid, vitamin $B_{6}$ and $B_{12}$, and various personal
C Biomed Central

() 2012 Huang et al; licensee BioMed Central Ltd. This is an Open Access article distributed under the terms of the Creative Commons Attribution License (http://creativecommons.org/licenses/by/2.0), which permits unrestricted use, distribution, and reproduction in any medium, provided the original work is properly cited. 


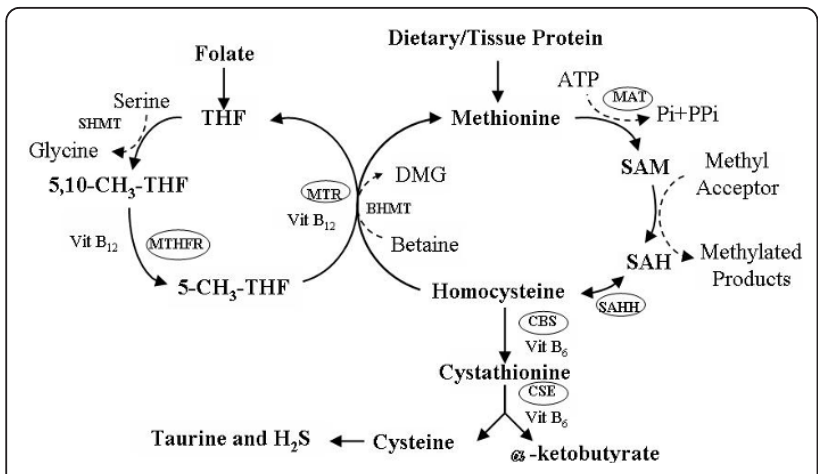

Figure 1 The diagram shows the enzyme points (in cycle) on which the effects of $n-3$ PUFA might operate in the homocysteine metabolic pathway of relevance. The critical genes in cycle were determined in present study. MTR: 5methyltetrahydrofolate-homocysteine methyltransferase; MAT: methionine adenosyl transferase; SAHH: S-adenosylhomocysteine hydrolases; CBS: Cystathionine $\beta$-synthase; CSE: Cystathionine $\boldsymbol{\gamma}$-lyase; MTHFR: Methylenetetrahydrafolate reductase; BHMT: Betainehomocysteine methyltransferase; DMG: Dimethylglycine; 5, 10- $\mathrm{CH}_{3}-$ THF: 5, 10-Methylene-Tetrahydrofolate; 5- $\mathrm{CH}_{3}$-THF: 5-MethylTetrahydrofolate; THF: Tetrahydrofolate; SHMT: Serine hydroxymethyl transferase; Pi: Orthophosphate; PPi: Pyrophosphate.

behaviours like physical inactivity and smoking [7]. Hcy metabolism is nutritionally regulated in part through the utilization of Hcy in the transsulfuration and remethylation pathways [8].

N-3 polyunsaturated fatty acids (PUFA) have protective effects on the cardiovascular system. Dietary intake of fish oil rich in n-3 PUFA leads to increased levels of n-3 PUFA in tissues [9], which is associated with reduced incidence of cardiovascular events via regulatory effects on blood pressure [10], serum/plasma triacylglycerol (TG) levels [11], antithrombotic effects and heart rate variability [12].

In a previous study, we reported that plasma Hcy was also significantly and negatively correlated with plasma phospholipids (PL) 22:6n-3 (DHA), total n-3 PUFA and n3/n-6 PUFA in healthy Australian men [13], and in middle aged and geriatric hyperlipaemic patients in Hangzhou [14]. In our cross sectional study, MAT1A genotypes were found to interact with dietary PUFA in determining plasma Hcy [8]. Furthermore, intervention studies and our recent meta-analysis document that the high consumption of $\mathrm{n}-3$ PUFA decreases plasma Hcy [15]. However, the mechanisms which may explain the relationship between $n-3$ PUFA and plasma Hcy levels are not yet fully understood. In a previous report we suggested that a possible mechanism for this relationship is that n-3 PUFA, especially $22: 6 n$ 3 , may modulate gene expression of an enzyme involved in the formation and metabolism of plasma Hcy [13].

Furthermore, in mammals, two genes (MAT1A and MAT2A), play an important role in human hepatocellular carcinoma, through facilitation of cancer cell growth [16]. In addition, SAH and Hcy is associated with invasion activities of hepatoma cells, increased level of plasma Hcy is a reflection of the degree of liver injury is more sensitive biochemical indicator of liver cirrhosis and liver cancer [17]. Therefore, to investigate the potential mechanism by which n-3 PUFA decrease Hcy in HepG-2 cell line, we conducted the cell culture to examine the nutritional regulation of n-3 PUFA (22:6n-3, DHA; 20:5n-3, EPA; 18:3n-3, ALA) on the mRNA expression of the genes encoding the key enzymes involved in Hcy metabolism.

\section{Methods}

\section{Cell Culture}

HepG-2 cell was purchased from Chinese Academy of Science. HepG-2 was cultured in DMEM medium (Inalco, USA) supplemented with $10 \%$ fetal bovine serum at $37^{\circ} \mathrm{C}$ in a humidified atmosphere of $5 \% \mathrm{CO}_{2}$. Cells were seeded in $25-\mathrm{cm}^{2}$ cell culture flasks or in 12wells plastic plate (Corning, USA), and grown to 50-70\% confluence.

\section{Treatment of fatty acid on HepG2 cells}

Prior to experiments, cells were washed twice with phosphate buffered saline (PBS) and once with serumfree DMEM medium without antibiotics. One milliliter containing $1 \times 10^{5}$ HepG2 cells was added into each well of the 12-wells plastic plate. For fatty acid treatment, the fatty acids were dissolved in ethanol [18]. After incubation at $37^{\circ} \mathrm{C}$ for $24 \mathrm{~h}$, the treatment groups were added with fresh culture media with a final fatty acids concentration (DHA, EPA, ALA, Cayman, USA) of $150 \mu \mathrm{M}$ [19], Controls were exposed to an equal concentration of ethanol to that in the fatty acid exposed samples. After the treatment with the fatty acids for 48 $\mathrm{h}$, the cells were collected for further experiments. Total RNA was extracted with Trizol reagent (Shinegene, China) as described by Zhang et al [20]. RNA was quantified with Nanodrop (Peqlab, Erlangen, Germany) and the RNA integrity number (RIN) was measured with Bioanalyzer (Agilent, Böblingen, Germany). No RNA was used with a RIN below 8.5. All experiments were performed in triplicate and repeated at least three times.

\section{Assay of the fatty acid composition in HepG2 cell membrane}

The cell was collected and centrifuged at 800 rcf. Total lipid content of cell membrane was extracted with chloroform/methanol solution (2:1, vol/vol) containing $50 \mathrm{mg} / \mathrm{L}$ butylated hydroxytoluene (Tokyo Kasei Kogyo Co., Ltd., Tokyo, Japan)., The PL fraction was separated by thin layer chromatography (TLC). The PL fatty acids were converted to methyl ester by using $2 \mathrm{~mL}$ of $2 \%$ $\mathrm{H}_{2} \mathrm{SO}_{4}$-methanol for 2 hours at $70^{\circ} \mathrm{C}$. The fatty acid 
methyl esters were prepared and separated by gas-liquid chromatography as described previously [21].

\section{Assay of mRNA expression of the critical genes involved in methionine metabolism \\ Real-time polymerase chain reaction}

Total RNA from ethanol or n-3 PUFA treated HepG2 cells were extracted by using the Trizol reagent (Shingene, Shanghai, China). The mRNA concentration and mRNA quality were determined by using the NanoDrop ND-2000. A value of $260 / 280$ ratio (1.8-2.0) indicates that the RNA is pure. The first strand cDNA was synthesized using cDNA sythesis kit (shinegene, Shanghai, China), the Real Time-PCR was conducted on iCycler PCR using the HotStart DNA Master SYBR Green I kit (Takara, Dalian, China) [22]. The primers used for the variety genes studied are shown in Table 1 . All PCR tests were carried out in duplicate with a final volume of $20 \mu \mathrm{L}$ containing cDNA. The thermal cycling conditions used were as follows: an initial DNA denaturation step at $95^{\circ} \mathrm{C}$ for 5 seconds, followed by 40 cycles of denaturation at $95^{\circ} \mathrm{C}$ for 5 seconds, primer annealing at optimal temperature for $20 \mathrm{~s}$, extension at $72^{\circ} \mathrm{C}$ for $30 \mathrm{~s}$, and an additional incubation step at $80-85^{\circ} \mathrm{C}$ for $30 \mathrm{~s}$ to measure SYBR Green I fluorescence. Finally, melt curve analysis was performed by slowly cooling the PCR from 95 to $60^{\circ} \mathrm{C}\left(0.5^{\circ} \mathrm{C}\right.$ per cycle $)$ with simultaneous measurement of the SYBR Green I signal intensity.

\section{The quantification of Real Time-PCR}

Gene expression was quantitated by using the comparative C (t) method [23].

Table 1 The primers used in the Real Time-PCR.

\begin{tabular}{|c|c|c|}
\hline Genes & $\begin{array}{l}\text { GenBank } \\
\text { accession } \\
\text { number }\end{array}$ & Primers \\
\hline \multirow[t]{2}{*}{ MAT } & NM_013283 & F: 5'- ACTTTGTTCCCGGGAGCTGTC -3' \\
\hline & & R: 5'- AACTGCATGCCAATTATTCTGCTG -3' \\
\hline \multirow[t]{2}{*}{ SAHH } & NM_000687 & F: 5'- CACCACAGGCTGTATTGACATCATC -3' \\
\hline & & R: 5'- GTCCAATGTTACACACAATGGCATC -3' \\
\hline \multirow[t]{2}{*}{ MTR } & NM_000254 & F: 5'-TAAGATTTGCAAAGGTTGGGTCTGA-3' \\
\hline & & R: 5'-CTGGACATACAGGTGGGAGTTGG-3' \\
\hline \multirow[t]{2}{*}{ MTHFR } & NM_005957 & F: 5'- TGTGTGAATTCTGCAACTAGCCAAG -3' \\
\hline & & R: 5'- ATGAGCCACCACACCTGCTG -3' \\
\hline \multirow[t]{2}{*}{ CSE } & NM_153742 & F: 5'-CCTTTGGCTCTGGGAGCTGATA-3' \\
\hline & & R: 5'-ATTAACAGACACCAGGCCCATTACA-3' \\
\hline \multirow[t]{2}{*}{ CBS } & NM_000071 & F: 5'-TGTGGGCACACCATCGAGA-3' \\
\hline & & R: 5'-AGCGTCACCATTCCCAGGATTA-3' \\
\hline \multirow[t]{2}{*}{$\beta$-actin } & NM_001101 & F: 5'- CGACAACGGCTCCGGCATGT-3' \\
\hline & & R: 5'- TGGGCCTCGTCGCCCACATA-3' \\
\hline
\end{tabular}

MAT: methionine adenosyltransferase; SAHH: S-adenosylhomocysteine hydrolase; MTR: 5-methyltetrahydrofolate-homocysteine methyltransferase; MTHFR: 5, 10-methylenetetrahydrofolate reductase; CSE: cystathionine $\gamma$-lyase; CBS: cystathionine $\beta$-synthase; $\beta$-action: housekeeping gene
$\mathrm{C}(\mathrm{t})$, the threshold cycle, is the number of cycles it takes for a sample to reach the level where the rate of amplification is the greatest during the exponential phase.

The quantification is used to determine the ratio between the quantity of a target molecule in a sample and in the calibrator (calibrator being e.g. untreated cell). The most common application of this method is the analysis of gene expression, e.g. comparisons of gene expression levels in different samples. Target molecule quantity is usually normalized with a housekeeping gene. Comparative $C(t)$ method can be used for relative quantification. Both the sample and calibrator data is first normalized against variation in sample quality and quantity. Normalized values, $\mathrm{C}(\mathrm{t}) \mathrm{s}$, are first calculated from following equations:

$$
\begin{aligned}
& \Delta \mathrm{C}(\mathrm{t})_{\text {sample }}=\mathrm{C}(\mathrm{t})_{\text {target }}-(\mathrm{t})_{\text {housekeeping gene }} \\
& \Delta \mathrm{C}(\mathrm{t})_{\text {calibrator }}=\mathrm{C}(\mathrm{t})_{\text {target }}-(\mathrm{t})_{\text {housekeeping gene }}
\end{aligned}
$$

The $\Delta \Delta C$ is then determined using the following formula:

$$
\Delta \Delta \mathrm{C}(\mathrm{t})=\Delta \mathrm{C}(\mathrm{t})_{\text {sample }}-\Delta \mathrm{C}(\mathrm{t})_{\text {calibrator }}
$$

Expression of the target gene normalized to the housekeeping gene and relative to the calibrator $=2^{-\Delta \Delta C(t)}$.

\section{Statistical analysis}

The data analyses were performed using an SPSS version 12 (SPSS Inc, Chicago, IL, USA) software program. All data are expressed as mean \pm SD. Statistical analysis was performed using post hoc tests in ANOVA; Differences between treatments were considered to be statistically significant at $\mathrm{p}<0.05$.

\section{Results}

The phospholipids fatty acid composition of cell membrane of HepG2 cell after the treatment of $n-3$ PUFA When compared with the control group, the concentration of $22: 6 n-3,20: 5 n-3,18: 3 n-3$ were significantly increased in the three treated groups respectively $(\mathrm{p}<$ $0.05)$; the level of n-3 PUFA was also significantly elevated in the three groups $(\mathrm{p}<0.05)$ (Table 2$)$.

\section{The mRNA expression of genes encoding the critical} enzymes involved in methionine metabolism in HepG2 cell was determined by Real Time-PCR after the treatment of $n-3$ PUFA

The expression levels of MTHFR were significantly increased in the DHA group $(p<0.05)$ and the ALA group ( $\mathrm{p}<0.05$ ) when compared with control (Figure $2 \mathrm{~A}$ );

Significantly decreased expression of MAT was observed in the three groups compared with control; 
furthermore, the level of MAT expression was significant lower in the DHA group than the ALA group ( $\mathrm{p}$ 0.05) (Figure 2B).

CSE expression was significantly increased in the DHA $(\mathrm{p}<0.05)$ and EPA groups $(\mathrm{p}<0.05)$ compared with control (Figure 2C).

No significant changes were seen in expression levels of SAHH, CBS, and MTR between the four groups (Figure $2 \mathrm{D}, \mathrm{E}, \mathrm{F})$.

\section{Discussion}

The objective of the present study was to investigate the regulatory effect of $n-3$ PUFA on mRNA expression of the genes encoding the critical enzymes involved in methionine metabolism.

We observed that n-3 PUFA up-regulates CSE and MTHFR mRNA expression and down-regulate MAT mRNA expression involved in Hcy metabolism. We suggest that this regulatory effect on gene expression is associated with decreased Hcy concentration.

A higher consumption of fish oil rich in n-3 PUFA is associated with reduced risk of cardiovascular events. Our previous studies have indicated that increased 22:6n-3 and n-3/n-6 PUFA in platelet and plasma PL is associated with decreased plasma Hcy $[13,14]$. Furthermore, meta-analysis confirms that n-3 PUFA decrease plasma Hcy [15]. In a previous animal study we have also demonstrated that 8 weeks of tuna oil treatment significantly decreases the plasma Hcy concentration in rats [24]. Yet HHcy is caused partly by genetic factors, including polymorphisms of genes encoding enzymes involved in Hcy metabolism, such as MTHFR, MTR, MTRR, and CBS [25,26]. A common mutation in MTHFR, MAT, and MTR results in a thermolabile variant with reduced activity $[27,28]$. Regulation of the gene

Table 2 The fatty acid composition of cell membrane of HepG2 cell (\%).

\begin{tabular}{lllll}
\hline Fatty acid & Control & DHA & EPA & ALA \\
\hline Total SFA & $7.5 \pm 1.1$ & $7.5 \pm 1.0$ & $7.8 \pm 1.2$ & $7.6 \pm 1.0$ \\
Total MUFA & $75.3 \pm 2.7$ & $75.3 \pm 3.1$ & $74.5 \pm 3.8$ & $74.2 \pm 2.9$ \\
Total n-6 PUFA & $13.4 \pm 1.3$ & $12.5 \pm 1.9$ & $13.4 \pm 2.0$ & $13.4 \pm 1.9$ \\
$18: 3 n-3$ & $1.3 \pm 0.1^{b}$ & $1.3 \pm 0.4^{b}$ & $1.5 \pm 0.2^{b}$ & $2.4 \pm 0.1^{a}$ \\
20:5n-3 & $1.3 \pm 0.2^{b}$ & $1.3 \pm 0.1^{b}$ & $1.6 \pm 0.4^{a}$ & $1.4 \pm 0.0^{b}$ \\
$22: 5 n-3$ & $0.4 \pm 0.0$ & $0.4 \pm 0.2^{b}$ & $0.5 \pm 0.1$ & $0.5 \pm 0.0$ \\
$22: 6 n-3$ & $0.8 \pm 0.2^{b}$ & $1.7 \pm 1.0^{a}$ & $0.7 \pm 0.1^{b}$ & $0.8 \pm 0.3^{b}$ \\
Total n-3 PUFA & $3.8 \pm 1.2^{b}$ & $4.7 \pm 1.7^{a}$ & $4.3 \pm 1.2^{a}$ & $5.1 \pm 0.9^{a}$ \\
\hline
\end{tabular}

The data was presented as Mean \pm SD.

$a, b, c$ Values within one row with different letters are significantly different ( $p$ $<0.5)$.

SFA: saturated fatty acid. MUFA: monounsaturated fatty acid. PUFA:

polyunsaturated fatty acid. DHA: docosahexaenoic acid. EPA: eicosapentaenoic acid. ALA: alpha-linolenic acid. expression of these critical genes using nutrients could make beneficial their coded enzyme activity.

To explain why n-3 PUFA decreases the level of Hcy, we examined the effect of n-3 PUFA on the mRNA expression of genes encoding the critical enzymes involved in methionine metabolism. In the present study, n-3 PUFA has been successfully incorporated into phospholipids of HepG2 cell membranes. Over the past 10 years, it has become evident that $n-3$ PUFA have a wide range of functions and are essential components of cells to maintain various functions and organelle structures, They can act as signaling molecules to regulate gene expression, encoding proteins forroles in fatty acid transport or metabolism, and act in differentiation, growth and metabolism $[29,30]$. Therefore, it is not surprising that the changes in PL fatty acid composition of cell membrane affected in the present studies can account for changes in mRNA expression of the critical genes involved in methionine metabolism, albeit with some selectivity.

We found that mRNA expression of MAT was significantly down-regulated by n-3PUFA. Thus, n-3 PUFA can affect the rate of SAM synthesis based on the activity of MAT. The intracellular SAM concentration is an important determinant of the fate of Hcy molecules [5]. But the resultant decrease in SAM synthesis via MAT would not stimulate SAH production which will be catalyzed to Hcy. The lack of recognizable change in $\mathrm{SAHH}$ expression presumably helps avoid an increase in Hcy, because the hydrolysis of SAH by the enzyme $\mathrm{SAHH}$ has been shown to be the sole intracellular source of Hcy [31]. SAHH expression was unchanged with n-3 PUFA when compared with control. Therefore, a decrease in SAH synthesis resulting from a decreased level of SAM would contribute to a reduction of Hcy formation.

SAM concentration plays an important role in the fate of Hcy molecules [5]. The potential mechanism is that SAM acts as not only as an allosteric inhibitor of MTHFR, but also an activator of CBS [32,33]. As such an effector, SAM suppresses the synthesis of N-5methyltetrahydrofolate which is an important substrate required for remethylation and promotes the initial reaction of transsulfuration (CBS). Hcy, when synthesized, acquires a methyl group from N-5-methyltetrahydrofolate or from betaine to form methionine via vitamin $B_{12}$ dependent MTHFR and MTR respectively in the remethylation pathway [5]. The impairment of the remethylation pathway due to an inadequate status of either folate or vitamin $B_{12}$ or to defects in the gene encoding for MTHFR will lead to a substantial increase in plasma Hcy concentration [34,35]. In the present study, the MTR expression was not significantly affected. However, MAT was down-regulated by DHA, 


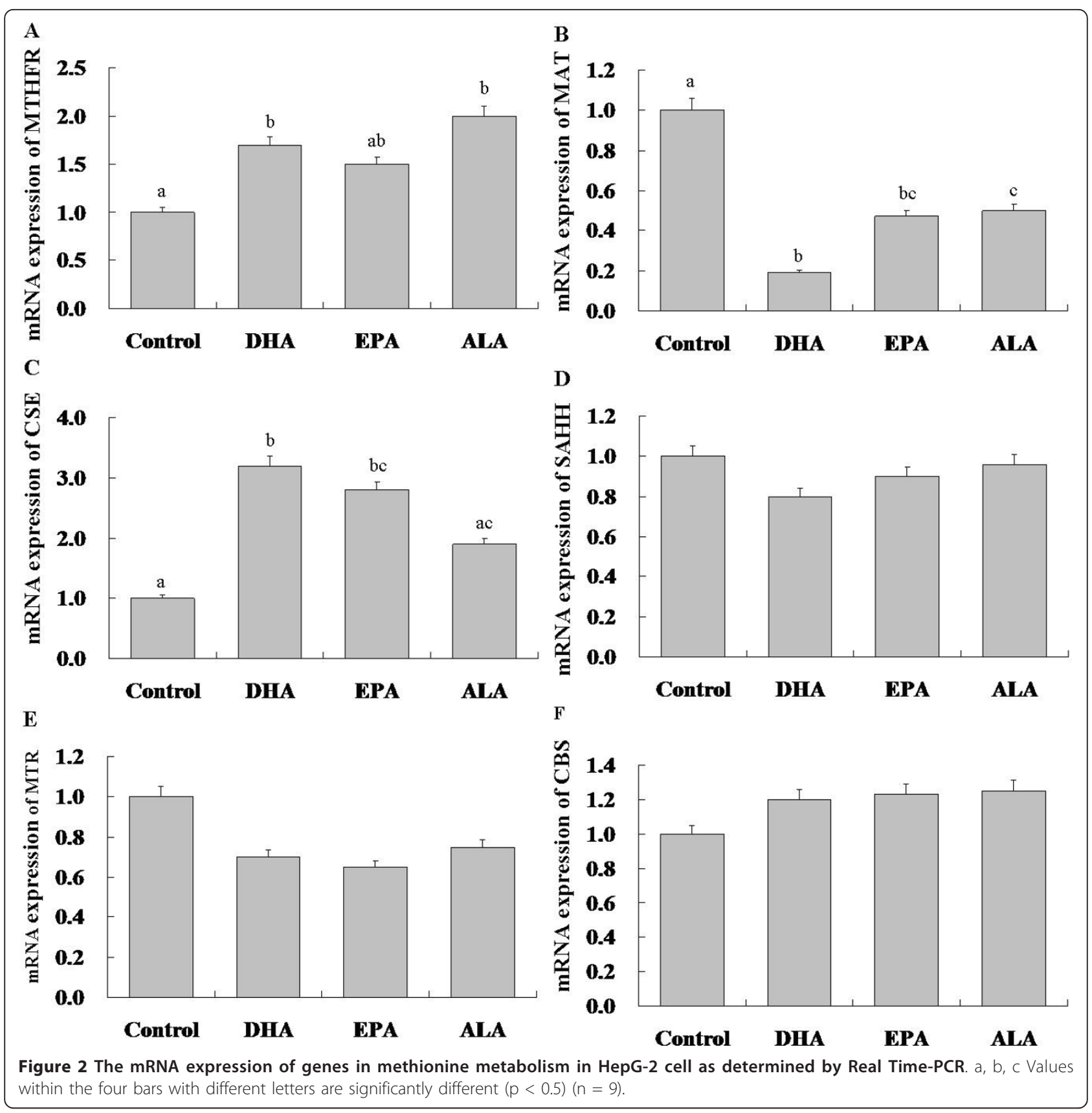

EPA, ALA; MTHFR was up-regulated by DHA and ALA when compared with control. Therefore, the decreased SAM concentration is insufficient for the inhibition of MTHFR; the result is an increased rate of N-5-methyltetrahydrofolate synthesis and Hcy remethylation [5], thereby reducing the level of Hcy.

In the transsulfuration pathway, Hcy condenses with serine to form cystathionine via CBS (using vitamin $\mathrm{B}_{6}$ as cofactor). Impairment in the transsulfuration pathway due to heterozygous defects in the CBS gene or inadequate levels of vitamin $B_{6}$ will lead to a very slight increase in fasting plasma Hcy levels [36,37]. CBS and CSE are the most important determinants in the transsulfuration pathway. The present study did not show a significant effect of n-3 PUFA on mRNA expression of CBS, However, the CSE mRNA expression was significantly up-regulated by DHA and EPA. CSE, which is a vitamin $\mathrm{B}_{6}$ dependent enzyme, catalyzes the conversion of cystathionine into cysteine, $\alpha$-ketobutyrate, taurine and $\mathrm{H}_{2} \mathrm{~S}$ and is the rate-limiting enzyme for the synthesis of cysteine from Hcy [38]. In a previous study, we also found that the enzyme activity and mRNA 
Table 3 The predicted transcription factors binding to fatty acid-responsive element in the promoter of the gene involved in Hcy metabolism

\begin{tabular}{|c|c|c|c|c|c|c|c|}
\hline Gene & GenelD & Transcript & Factor & Name(s) & Chrom & Start & End \\
\hline$\overline{M T R}$ & 4548 & NM_000254 & MA0066 & PPARG & chr1 & $236,956,831$ & $236,956,850$ \\
\hline MTR & 4548 & NM_000254 & MA0061 & NF-kappaB & chr1 & $236,958,560$ & $236,958,569$ \\
\hline $\mathrm{HHCY}$ & 191 & NM_000687 & MA0061 & NF-kappaB & chr20 & 32891257 & 32891266 \\
\hline HHCY & 191 & NM_000687 & M00242 & PPARalpha:RXRalpha & chr20 & 32891807 & 32891826 \\
\hline $\mathrm{HHCY}$ & 191 & NM_000687 & M00964 & PXR, CAR, LXR, FXR & chr20 & 32892802 & 32892813 \\
\hline $\mathrm{HHCY}$ & 191 & NM_000687 & T00720 & RAR-gamma & chr20 & 32891787 & 32891797 \\
\hline $\mathrm{HHCY}$ & 191 & NM_000687 & MA0074 & RXRA::VDR & chr20 & 32891381 & 32891395 \\
\hline CSE & 1491 & NM_153742 & M00774 & NF-kappaB & chr1 & 70876211 & 70876222 \\
\hline CSE & 1491 & NM_153742 & M00762 & PPAR, HNF-4, COUP, & chr1 & 70875793 & 70875805 \\
\hline CSE & 1491 & NM_153742 & M00518 & PPARalpha:RXRalpha & chr1 & 70876539 & 70876552 \\
\hline CSE & 1491 & NM_153742 & MA0065 & PPARG::RXRA & chr1 & 70876537 & 70876553 \\
\hline CSE & 1491 & NM_153742 & MA0074 & RXRA::VDR & chr1 & 70875356 & 70875369 \\
\hline CSE & 1491 & NM_153742 & T01331 & RXR-alpha & chr1 & 70876645 & 70876657 \\
\hline CBS & 875 & NM_000071 & MA0061 & NF-kappaB & chr21 & 44496816 & 44496825 \\
\hline CBS & 875 & NM_000071 & T00694 & PPAR-alpha & chr21 & 44496841 & 44496851 \\
\hline CBS & 875 & NM_000071 & MA0073 & RREB1 & chr21 & 44496183 & 44496202 \\
\hline CBS & 875 & NM_000071 & MA0074 & RXRA::VDR & chr21 & 44496362 & 44496376 \\
\hline CBS & 875 & NM_000071 & T01349 & RXR-beta & chr21 & 44496925 & 44496932 \\
\hline MAT1A & 4143 & NM_000429 & T05257 & CAR2:RXR-alpha & chr10 & 82051245 & 82051257 \\
\hline MAT1A & 4143 & NM_000429 & M00631 & FXR/RXR-alpha & chr10 & 82050669 & 82050682 \\
\hline MAT1A & 4143 & NM_000429 & MA0061 & NF-kappaB & chr10 & 82049620 & 82049629 \\
\hline MAT1A & 4143 & NM_000429 & MA0105 & NFKB1 & chr10 & 82049504 & 82049514 \\
\hline MAT1A & 4143 & NM_000429 & T02529 & PPAR-gamma1 & chr10 & 82051368 & 82051378 \\
\hline MAT1A & 4143 & NM_000429 & MA0074 & RXRA::VDR & chr10 & 82050026 & 82050040 \\
\hline MAT1A & 4143 & NM_000429 & T01331 & RXR-alpha & chr10 & 82050924 & 82050936 \\
\hline MTHFR & 4524 & NM_005957 & MA0066 & PPARG & chr1 & 11866220 & 11866239 \\
\hline MTHFR & 4524 & NM_005957 & T05313 & FXR:RXR-alpha & chr1 & 11867028 & 11867042 \\
\hline MTHFR & 4524 & NM_005957 & M00774 & NF-kappaB & chr1 & 11866612 & 11866623 \\
\hline MTHFR & 4524 & NM_005957 & M00518 & PPARalpha:RXRalpha & chr1 & 11867952 & 11867966 \\
\hline MTHFR & 4524 & NM_005957 & MA0065 & PPARG::RXRA & chr1 & 11867331 & 11867347 \\
\hline MTHFR & 4524 & NM_005957 & T02529 & PPAR-gamma1 & chr1 & 11867417 & 11867427 \\
\hline MTHFR & 4524 & NM_005957 & M00964 & PXR, CAR, LXR, FXR & chr1 & 11866787 & 11866798 \\
\hline
\end{tabular}

The predicted transcription factors (RXR-alpha) binding to n-3 PUFA-RE in the promoter of MTHFR, CSE, and MAT using web based software Mapper: http:// genome.ufl.edu/mapper/.

expression of CSE was up-regulated after 8 weeks of tuna oil supplementation [24]. Thus up-regulated CSE mRNA expression expedited the degradation of cystathionine. This means that the transsulfuration reaction will move in a direction beneficial for a decrease in Hcy. Recently, elevated $\mathrm{H}_{2} \mathrm{~S}$ has been proposed as a new gasotransmitter in the modulation of cardiovascular function $[39,40]$. Hcy- $\mathrm{H}_{2} \mathrm{~S}$ metabolic imbalance could be an important mechanism in the pathogenesis of hypertension [40]. The up-regulated endogenous $\mathrm{H}_{2} \mathrm{~S} / \mathrm{CSE}$ pathway in pulmonary arteries by l-arginine is involved in the mechanisms by which 1-arginine influences pulmonary hypertension [41]. The present findings also suggest that $\mathrm{n}-3$ PUFA may ameliorate hypertension by decreasing Hcy as well as by increasing $\mathrm{H}_{2} \mathrm{~S}$ as a result of up-regulated CSE gene expression.
The potential mechanisms by which $n-3$ PUFA regulate CSE, MAT, and MTHFR gene expression are not clear. Previous studies have demonstrated that n-3 PUFA governs oxidative gene expression involved in lipid metabolism by activating the transcription factor peroxisome proliferator-activated receptor (PPAR) alpha. N-3 PUFA suppress lipogenic gene expression by reducing the nuclear abundance and DNA-binding affinity of transcription factors responsible for imparting insulin and carbohydrate control to lipogenic and glycolytic genes. In particular, n-3 PUFA suppress the nuclear abundance and expression of sterol regulatory element binding protein-1 and reduce the DNA-binding activities of nuclear factor Y, Sp1 and possibly hepatic nuclear factor-4 [30]. Furthermore, Narayanan et al reported that DHA regulates genes and transcription factors in human colon 
cancer cells [42]; they showed that DHA down regulates nine members of the RNA II polymerases, transcription co-repressor associated protein and enhancer binding proteins such as AP2, in addition to changes in the expression of the zinc finger group of transcription factors and also altered expression of peroxisome proliferators (PPAR alpha and gamma) [42]. Based on these data, we speculate that a cis-acting n-3 PUFA responsive element ( $n-3$ PUFA-RE) may be located in the promoter region of the n-3 PUFA-regulated genes. To alter gene transcription, a transcription factor (putative n-3 PUFAbinding protein) could bind to $\mathrm{n}-3$ PUFA-RE and block or enhance transcription. In regard to this hypothesis, we found that the predicted transcription factors (RXRalpha) bind to n-3 PUFA-RE in the promoter of MTHFR, CSE, and MAT though use of web based software Mapper: http://genome.ufl.edu/mapper/ (Table 3). Our hypothesis warrants further investigation.

\section{Conclusions}

N-3 PUFA up-regulates CSE and MTHFR mRNA expression and down-regulates MAT mRNA expression involved in Hcy metabolism. This regulatory effect of n3 PUFA on critical gene expression is associated with decreased Hcy concentration. Our findings provide a basis for verification of mechanisms by which n-3 PUFA decreases plasma Hcy.

\section{List of Abbreviations}

SAHH: S-adenosylhomocysteine hydrolase; CBS: cystathionine $\beta$-synthase; CSE: cystathionine $\gamma$-lyase; MAT: methionine adenosyltransferase (Sadenosylmethionine synthase; methionine activating enzyme); MTR: 5methyltetrahydrofolate-homocysteine methyltransferase; MTHFR: methylenetetrahydrofolate reductase; SAM: S-adenosylmethionine; SAH: S adenosylhomocysteine; THF: tetrahydrofolate.

\section{Acknowledgements}

This work was supported by a grant from National High Technology Research and Development Program of China (No. N20080753), the National Natural Science Foundation of China (No.30972464) and the Ph.D. Programs Foundation of Ministry of Education of China (No. 20070335025).

\section{Author details}

'Department of Food Science and Nutrition, Zhejiang University, Hangzhou, 310029 China. ${ }^{2}$ APCNS Centre of Nutrition and Food Safety, Hangzhou, China. ${ }^{3}$ National Health Research Institutes, Zhunan, Taiwan.

\section{Authors' contributions}

TH carried out the studies, analyzed data and drafted the manuscript; MLW and DL participated in manuscript preparation; and MLW and DL participated in the project design. All authors read and approved the final manuscript.

\section{Competing interests}

The authors declare that they have no competing interests.

Received: 30 September 2010 Accepted: 19 January 2012 Published: 19 January 2012
References

1. Huang T, Yuan G, Zhang Z, Zou Z, Li D: Cardiovascular pathogenesis in hyperhomocysteinemia. Asia Pac J Clin Nutr 2008, 17(4):8-16.

2. McCully KS: Vascular pathology of homocysteinemia: implications for the pathogenesis of arteriosclerosis. Am J Pathol 1969, 56(1):111-128.

3. Kaul S, Zadeh AA, Shah PK: Homocysteine hypothesis for atherothrombotic cardiovascular disease: not validated. J Am Coll Cardiol 2006, 48(5):914-923.

4. Sofi F, Marcucci R, Bolli P, Giambene B, Sodi A, Fedi S, Menchini U, Gensini GF, Abbate R, Prisco D: Low vitamin B6 and folic acid levels are associated with retinal vein occlusion independently of homocysteine levels. Atherosclerosis 2008, 198(1):223-227.

5. Selhub J: Homocysteine metabolism. Annu Rev Nutr 1999, 19:217-246.

6. Hamelet J, Demuth K, Paul JL, Delabar JM, Janel N: Hyperhomocysteinemia due to cystathionine beta synthase deficiency induces dysregulation of genes involved in hepatic lipid homeostasis in mice. J Hepatol 2007, 46(1):151-159.

7. Refsum H, Ueland PM, Nygard O, Vollset SE: Homocysteine and cardiovascular disease. Annu Rev Med 1998, 49:31-62.

8. Huang T, Tucker K, Lee Y, Crott J, Parnell L, Shen J, Smith C, Ordovas J, Li D, Lai C: MAT1A variants modulate the effect of dietary fatty acids on plasma homocysteine concentrations. Nutr Metab Cardiovasc Dis 2010.

9. Hu FB, Stampfer MJ, Manson JE, Rimm EB, Wolk A, Colditz GA, Hennekens $\mathrm{CH}$, Willett WC: Dietary intake of alpha-linolenic acid and risk of fatal ischemic heart disease among women. Am J Clin Nutr 1999, 69(5):890-897.

10. Morris MC, Sacks F, Rosner B: Does fish oil lower blood pressure? A metaanalysis of controlled trials. Circulation 1993, 88(2):523-533.

11. Svaneborg $\mathrm{N}$, Moller JM, Schmidt EB, Varming $\mathrm{K}$, Lervang HH, Dyerberg J: The acute effects of a single very high dose of $n-3$ fatty acids on plasma lipids and lipoproteins in healthy subjects. Lipids 1994, 29(2):145-147.

12. Christensen JH, Skou HA, Madsen T, Torring I, Schmidt EB: Heart rate variability and $n-3$ polyunsaturated fatty acids in patients with diabetes mellitus. J Intern Med 2001, 249(6):545-552.

13. Li D, Mann NJ, Sinclair AJ: A significant inverse relationship between concentrations of plasma homocysteine and phospholipid docosahexaenoic acid in healthy male subjects. Lipids 2006, 41(1):85-89.

14. Li D, Yu XM, Xie HB, Zhang YH, Wang Q, Zhou XQ, Yu P, Wang LJ: Platelet phospholipid n-3 PUFA negatively associated with plasma homocysteine in middle-aged and geriatric hyperlipaemia patients. Prostaglandins Leukot Essent Fatty Acids 2007, 76(5):293-297.

15. Huang T, Zheng J, Chen Y, Yang B, Wahlqvist ML, Li D: High consumption of omega-3 polyunsaturated fatty acids decrease plasma homocysteine: A meta-analysis of randomized, placebo-controlled trials. Nutrition 2011.

16. Lu SC, Mato JM: S-Adenosylmethionine in cell growth, apoptosis and liver cancer. Journal of gastroenterology and hepatology 2008, 23(Suppl 1): S73-77.

17. Yang TH, Hu ML: Intracellular levels of S-adenosylhomocysteine but not homocysteine are highly correlated to the expression of $\mathrm{nm} 23-\mathrm{H} 1$ and the level of 5-methyldeoxycytidine in human hepatoma cells with different invasion activities. Nutr Cancer 2006, 55(2):224-231.

18. Dimri M, Bommi PV, Sahasrabuddhe AA, Khandekar JD, Dimri GP: Dietary omega-3 polyunsaturated fatty acids suppress expression of EZH2 in breast cancer cells. Carcinogenesis 2010, 31(3):489-495.

19. Colquhoun A: Mechanisms of action of eicosapentaenoic acid in bladder cancer cells in vitro: alterations in mitochondrial metabolism, reactive oxygen species generation and apoptosis induction. J Urol 2009, 181(4):1885-1893.

20. Zhang X, Zhu Z, Luo G, Zheng L, Nilsson-Ehle P, Xu N: Liver X receptor agonist downregulates hepatic apoM expression in vivo and in vitro. Biochem Biophys Res Commun 2008, 371(1):114-117.

21. Li D, Sinclair A, Wilson A, Nakkote S, Kelly F, Abedin L, Mann N, Turner A: Effect of dietary alpha-linolenic acid on thrombotic risk factors in vegetarian men. Am J Clin Nutr 1999, 69(5):872-882.

22. Habermann N, Schon A, Lund EK, Glei M: Fish fatty acids alter markers of apoptosis in colorectal adenoma and adenocarcinoma cell lines but fish consumption has no impact on apoptosis-induction ex vivo. Apoptosis 2010, 15(5):621-630.

23. Uthus EO, Brown-Borg HM: Methionine flux to transsulfuration is enhanced in the long living Ames dwarf mouse. Mech Ageing Dev 2006, 127(5):444-450. 
24. Huang T, Wahlqvist ML, Li D: Docosahexaenoic acid decreases plasma homocysteine via regulating enzyme activity and mRNA expression involved in methionine metabolism. Nutrition 2010, 26(1):112-119.

25. Selhub J, Jacques PF, Wilson PW, Rush D, Rosenberg $\mid H$ : Vitamin status and intake as primary determinants of homocysteinemia in an elderly population. JAMA 1993, 270(22):2693-2698.

26. Meyer K, Fredriksen A, Ueland PM: High-level multiplex genotyping of polymorphisms involved in folate or homocysteine metabolism by matrix-assisted laser desorption/ionization mass spectrometry. Clin Chem 2004, 50(2):391-402.

27. Weisberg I, Tran P, Christensen B, Sibani S, Rozen R: A second genetic polymorphism in methylenetetrahydrofolate reductase (MTHFR) associated with decreased enzyme activity. Mol Genet Metab 1998, 64(3):169-172.

28. Klerk M, Lievers KJ, Kluijtmans LA, Blom HJ, den Heijer M, Schouten EG, Kok FJ, Verhoef P: The $2756 \mathrm{~A}>\mathrm{G}$ variant in the gene encoding methionine synthase: its relation with plasma homocysteine levels and risk of coronary heart disease in a Dutch case-control study. Thromb Res 2003, 110:(2-3):87-91.

29. Duplus $\mathrm{E}$, Glorian M, Forest C: Fatty acid regulation of gene transcription. J Biol Chem 2000, 275(40):30749-30752.

30. Clarke SD: Polyunsaturated fatty acid regulation of gene transcription: A molecular mechanism to improve the metabolic syndrome. J Nutr 2001, 131(4):1129-1132.

31. Finkelstein JD: Pathways and regulation of homocysteine metabolism in mammals. Semin Thromb Hemost 2000, 26(3):219-225.

32. Finkelstein JD, Martin JJ: Methionine metabolism in mammals. Distribution of homocysteine between competing pathways. J Biol Chem 1984, 259(15):9508-9513

33. Kutzbach C, Stokstad EL: Mammalian methylenetetrahydrofolate reductase. Partial purification, properties, and inhibition by Sadenosylmethionine. Biochim Biophys Acta 1971, 250(3):459-477.

34. Brattstrom L, Israelsson B, Norrving B, Bergqvist D, Thorne J, Hultberg B, Hamfelt A: Impaired homocysteine metabolism in early-onset cerebral and peripheral occlusive arterial disease. Effects of pyridoxine and folic acid treatment. Atherosclerosis 1990, 81(1):51-60

35. Wilcken DE, Dudman NP, Tyrrell PA, Robertson MR: Folic acid lowers elevated plasma homocysteine in chronic renal insufficiency: possible implications for prevention of vascular disease. Metabolism 1988, 37(7):697-701.

36. Brattstrom L, Israelsson B, Lindgarde F, Hultberg B: Higher total plasma homocysteine in vitamin B12 deficiency than in heterozygosity for homocystinuria due to cystathionine beta-synthase deficiency. Metabolism 1988, 37(2):175-178.

37. Miller JW, Nadeau MR, Smith D, Selhub J: Vitamin B-6 deficiency vs folate deficiency: comparison of responses to methionine loading in rats. Am J Clin Nutr 1994, 59(5):1033-1039.

38. Diwakar $L$, Ravindranath $V$ : Inhibition of cystathionine-gamma-lyase leads to loss of glutathione and aggravation of mitochondrial dysfunction mediated by excitatory amino acid in the CNS. Neurochem Int 2007, 50(2):418-426.

39. Green PS, Mendez AJ, Jacob JS, Crowley JR, Growdon W, Hyman BT Heinecke JW: Neuronal expression of myeloperoxidase is increased in Alzheimer's disease. J Neurochem 2004, 90(3):724-733.

40. Chen L, Ingrid S, Ding YG, Liu Y, Qi JG, Tang CS, Du JB: Imbalance of endogenous homocysteine and hydrogen sulfide metabolic pathway in essential hypertensive children. Chin Med J (Engl) 2007, 120(5):389-393.

41. Yanfei W, Lin S, Junbao D, Chaoshu T: Impact of L-arginine on hydrogen sulfide/cystathionine-gamma-lyase pathway in rats with high blood flow-induced pulmonary hypertension. Biochem Biophys Res Commun 2006, 345(2):851-857.

42. Narayanan BA, Narayanan NK, Reddy BS: Docosahexaenoic acid regulated genes and transcription factors inducing apoptosis in human colon cancer cells. Int J Oncol 2001, 19(6):1255-1262.

doi:10.1186/1475-2891-11-6

Cite this article as: Huang et al: Effect of $n-3$ polyunsaturated fatty acid on gene expression of the critical enzymes involved in homocysteine metabolism. Nutrition Journal 2012 11:6

\section{Submit your next manuscript to BioMed Central and take full advantage of:}

- Convenient online submission

- Thorough peer review

- No space constraints or color figure charges

- Immediate publication on acceptance

- Inclusion in PubMed, CAS, Scopus and Google Scholar

- Research which is freely available for redistribution

Submit your manuscript at www.biomedcentral.com/submit
Biomed Central 